\title{
NEUROCIENCIA Y DERECHO. LA DECISIÓN EMOCIONAL DEL JUEZ EN EL PROCESO JUDICIAL
}

\author{
Neuroscience and Law. The judge's emotional decision \\ in the judicial process
}

\author{
Jhonatan Samuel Peña Carlos* \\ Universidad Andina del Cusco
}

Aceptación: 2/10/2017

\section{Resumen}

Toda decisión judicial tiene que estar revestida de la garantía de imparcialidad, esta decisión, por lo tanto, debe tener una justificación racional por parte del juez; sin embargo, advertimos que dicha decisión está impulsada por emociones, aspecto que únicamente puede abordarse a través de una perspectiva Neurocientífica. En el artículo se formularán propuestas con la finalidad de lograr, en la mayor medida posible, la imparcialidad en las decisiones judiciales, una de ellas relacionada con el control de las emociones por medio de la manipulación del contexto en el que surgen —educación emocional—, y la otra es diseñar una técnica procedimental en el proceso, considerando un juez de instrucción y otro de sentencia.

Palabras clave: Neurociencia; fuentes del Derecho; ordenamiento normativo; emociones y comunicación procesal.

\section{Abstract}

Every judicial decision must be supported by the guarantee of impartiality, therefore this decision should be covered by a rational justification by the judge, nevertheless we noticed that this decision is driven by emotions, an aspect that can only be presented through a Neuroscientific perspective. In this paper, as far as possible, proposals will be formulated with the aim of achieving, impartiality in judicial decisions, one of them related to the control of the emotions by manipulating the context in which they arise - motional education- and the other is to design a procedural technique in the process, considering an investigating judge and a sentencing judge.

Keywords: Neuroscience; sources of Law; normative ordering; emotions and procedural communication.

* Integrante del Centro de Investigación de Derecho Procesal, asistente en el Segundo Juzgado de Paz Letrado de Wanchaq. Estudiante de la Universidad Andina del Cusco. 


\section{INTRODUCCIÓN}

En los últimos años, la Neurociencia y sus avances de investigación científica, de análisis de la estructura y funcionamiento del cerebro han causado impactos significativos en el entendimiento de distintas disciplinas científicas; la dogmática jurídica no está exenta a ella, ya que puso en debate, y hasta ahora, el entendimiento de la noción del libre albedrío y la responsabilidad.

En este trabajo, me propongo de manera modesta tratar de analizar, en primer lugar, la relación existente entre Neurociencia y Derecho, para luego abarcar la decadencia del positivismo, ello en razón de que resulta indispensable mencionar que el Derecho requiere no solo de una base normativa legislada — verbalizada — sino también de una base muda — no verbalizada—; esto genera una nueva forma de entender lo procesal, no solo por la nueva configuración del sistema de fuentes, que también abordaremos, sino porque esa nueva faz sistémica de los orígenes del Derecho que tienen un componente redefinido desde la teoría del Derecho tácito — mudo-.

Así mismo, intentaré explicar el papel de las emociones en el proceso de la toma de decisiones, para luego desarrollar un ecosistema conjuntivo —interacción procesal— conformado por el protagonismo del juez y de las partes judiciales, con el fin de explicar la imperceptibilidad racional de la comunicación procesal no verbalizada, no racionalizada, es decir, todos los rasgos subjetivos que son un factor importante y silencioso en el proceso para la toma de una decisión judicial por parte del juez.

Espero que el conjunto de estas reflexiones logre introducir nuevamente la teoría de las emociones en la dogmática jurídica. En fin, si bien resulta un poco novedoso incorporar la palabra Neurociencia al Derecho, también es necesario — en proyección al futuro de esta ciencia social — la búsqueda de aquella perfectibilidad del otorgamiento o, mejor, prestación de justicia. Se requiere, entonces, adoptar todas las medidas necesarias en la tarea de búsqueda continua de la justicia, así como abarcar más temáticas y realidades para resolver los conflictos intersubjetivos. Neurociencia significa, de esta manera, esperanza de revolucionar la justicia para el mañana.

\section{NEUROCIENCIA Y DERECHO}

En palabras del profesor Jordi Nieva, en Derecho, menos mal que se dejó de hablar únicamente de ello, Derecho, como si fuera una religión. Es claro 
que dicha ciencia social debe nutrirse de otras ciencias, porque el Derecho trata con la sociedad, con las personas, por ende la Neurociencia tiene como desafío, en la dogmática jurídica, examinar y conocer los pensamientos y razonamientos de una persona en sociedad.

Es a partir de la investigación Neuroscience and the Law. Brain, Mind, and the Scales of Justice ${ }^{l}$, que emergió una interacción entre las dos disciplinas académicas - Neurociencia y Derecho-, las cuales han impactado una con otra, resultando entre ambas estudios interdisciplinarios; un ejemplo de esta cooperación científica, es la aplicación de técnicas neurofisiológicas y psicofisiológicas $^{2}$ en la investigación policial, en el ámbito del Derecho Penal, gestando así nuevas estrategias de investigación para la explicación de la conducta y la valoración de la responsabilidad criminal.

El neurólogo Facundo Manes señala que «la Neurociencia estudia la organización y el funcionamiento del sistema nervioso y cómo los diferentes elementos interactúan y dan origen a la conducta de los seres humanos»; de la misma manera, concluye que la Neurociencia estudia, además, las emociones, la conciencia, la toma de decisiones y todas las acciones sociopsicológicas de la persona.

El primer experimento que dio luz a la complejidad de nuestro cerebro es el suceso que padeció Phineas Gage ${ }^{4}$, un capataz de ferrocarriles que trabajaba en Cavendish (Vermont, EE. UU.), en la construcción de una línea ferroviaria. Horas antes de que Phineas sufriera el accidente, que se narrara infra, era considerado un colaborador amable, educado, eficiente, responsable y capaz.

Phineas, en instantes en que realizaba su trabajo, por descuido presionó uno de los explosivos que provocaron que una barra - tamaño de un palo de escoba- le atravesara el cráneo por la mejilla izquierda y saliera por el

1 GARLAN, Brent. Neuroscience and the Law. Brain, Mind, and the Scales of Justice, New York/ Washintong: DANA, AAAS, 2004. Cfr. Semir Zeki y Oliver Goodenough: Law and the Brain, Oxford: Oxford University Press, 2006.

2 Así a modo de ejemplo se pueden citar técnicas como el diagnóstico de Encefalograma (EEG), P300, la tomografía axial computarizada (TAC), la tomografía por positrones (PET), la tomografía computarizada de emisión monofotónica (SPECT), entre otras.

3 FACUNDO, Mateo. Usar el cerebro, conocer nuestra mente para vivir mejor. Buenos Aires: Editorial Planeta, 2014, p. 25.

4 El voluminoso trabajo de Malcolm Mac Millan ha servido para aclarar los múltiples errores en la documentación de la historia de Phineas Gage, así como para demostrar las tergiversaciones que se produjeron, muchas por el mero afán de colorear la situación y otras por deficiencias en la competencia de especialistas que han narrado episodios asociados al caso. 
córtex anterior de cerebro ${ }^{5}$, es decir, el lóbulo frontal fue completamente atravesado. Milagrosamente, contra todo pronóstico, fue dado de alta después de dos meses de recuperación, a razón de que Gage no presentaba ninguna alteración en su conciencia tras el brutal accidente, es más, todo su ámbito racional, como su capacidad de memoria, el uso del lenguaje, su atención y su razonamiento básico se encontraban en perfectas condiciones; sin embargo, tiempo después empezó a mostrar conductas negativas, cambios de personalidad, Phineas Gage se convirtió en un hombre irregular, rebelde, blasfemo e impaciente.

¿Cómo se explica este suceso?, Gabe se convirtió en un caso experimental que permitía demostrar que el cerebro no está únicamente conformado en su integridad por zonas racionales, sino también por zonas emocionales, las cuales están alojadas en el lóbulo frontal de nuestro cerebro. Así se pudo explicar que los cambios de comportamiento de un sujeto estaban relacionados con un traumatismo cerebral en una zona específica, lo cual alteraba aspectos de personalidad, la emoción e interacción social.

A partir de este hecho, se pudo entender de mejor manera el funcionamiento del lóbulo frontal, ya antes se le había considerado como estructuras cerebrales sin función ni relación con el comportamiento humano. En consecuencia, Phineas Gabe al haber sufrido el accidente — narrado líneas arriba - ya no era la misma persona, es decir, pasó a ser de una persona amable a ser una persona odiosa, grosera y mal educada, pese a que todas sus capacidades racionales se encontraban normales.

«Pero no fue hasta el uso de la neuroimagen ${ }^{6}$ que se hizo posible una localización más certera de las zonas cerebrales que pudieron correlacionarse con cuestiones de personalidad ${ }^{7}$, es así que en un reciente experimento, se pidió a una variedad de hombres que puedan clasificar las fotos de 25 mujeres en función de su atractivo físico - belleza-. El resultado fue el siguiente, que la mayoría de los hombres se sentían atraídos por las mujeres que tenían las pupilas dilatadas, lo crucial fue que ninguno de los hom-

5 Los informes originales fueron elaborados por el Dr. John Martyn Harllow (1819-1907), quien presentó el caso a las sociedades médicas en aquel entonces.

6 Entendida la neuroimagen como el conjunto de técnicas que permiten obtener imágenes del cerebro.

7 NARVAEZ, Maribel. «El impacto de la neurociencia sobre el derecho: el caso de la responsabilidad subjetiva». En Revista Telemática de Filosofía del Derecho n. ${ }^{\circ}$ 15, Madrid, 2012, pp. 195-230. 
bres se había percatado de esta característica en ellas; lo extraordinario fue que ninguno tenía conciencia de que esto había influenciado en su decisión, nadie dijo "he observado que sus pupilas eran dos milímetros más grandes en esta foto que en esta otra ${ }^{8}$, solo se sintieron atraídos por determinadas mujeres. ¿Entonces quién decide?

Con el uso de la neuroimagen se pudo advertir que el cerebro de los hombres sometidos al experimento sí sabía que los ojos dilatados de las mujeres tenían relación con la predisposición y reproducción sexual, pero esto no lo sabían los hombres que participaron en el estudio. Cuando los hombres eligieron a las mujeres más atractivas para ellos, no tenían idea que la elección en realidad no era suya, sino que pertenecía a los programas más profundos que han quedado grabados en el cerebro — creencias y emociones-.

Lo impresionante de ambos ejemplos es que nada de lo que ocurre en nuestro cerebro está bajo nuestro control, «la mente consciente no se halla en el centro de la acción del cerebro, sino más bien en un borde lejano, y no oye más que susurros de la actividad" ${ }^{9}$ cerebral, por ende, no hacemos lo que queremos sino que en realidad queremos lo que hacemos de manera predispuesta.

En ese sentido, estaríamos controlados por nuestro cerebro, nuestras acciones y decisiones no serían más que órdenes provenientes de esta materia gris de 2 kilos, en consecuencia la voluntad o el libre albedrío sería una mera ilusión.

En este contexto, la repercusión de la Neurociencia en el Derecho puede expresarse en la determinación, por ejemplo, de la capacidad de una persona, en su imputabilidad, en la verificación de psicopatías y alteraciones cerebrales que puedan modificar su comportamiento; pero no solo ello, también puede tener injerencia en el desarrollo del proceso jurisdiccional, específicamente en la imparcialidad e independencia judicial en la toma de decisiones por parte de los jueces.

Finalmente, tenemos que recordar que hubo una etapa de ignorancia científica, la cual siempre estaba convalidada por un criterio positivista, ahora nos damos cuenta que la ley no es perfecta ni suficiente para imputar ni

8 EAGLEMAN, David. Incógnito. Las vidas secretas del cerebro. Barcelona: Editorial Anagrama, 2013, p. 13.

$9 \quad$ Ibidem, pp. 18 y ss. 
para juzgar, no es el todo, por ende hay una decadencia del positivismo y a partir de ello habría una nueva clasificación de fuentes del Derecho que pueden ser mudas tácitas, por ejemplo la interacción de sujetos, estas últimas que pueden ser expresadas y estudiadas a partir de la Neurociencia, y que pueden ser incorporadas al entendimiento distinto y completo del ordenamiento normativo.

\section{DETRÁS DEL POSITIVISMO}

Durante mucho tiempo, el imperio de la ley o positivismo jurídico, se aseguró, en la doctrina, que el Derecho legal —objetivo o legislativoactuaba en forma espontánea en la sociedad. Es decir, el gran complejo interactivo de los individuos en sociedad funcionaba siempre al calor de la vigencia de la ley — escrita y, por tanto, verbalizada — aun cuando las personas no las invocaran en sus quehaceres cotidianos, desde lo más simple como hacer cola para comprar un producto, hasta un contrato con traditio brevi manu, etc.

Es de suponer, por ejemplo, que hacer cola no requiere una remisión a reglas de cómo hacer colas, estas existen de manera tácita. Sin embargo, el discurso del positivismo señalaba que las actuaciones espontáneas, como hacer colas, eran hechas por remisión y por actuación única y exclusiva de las reglas impuestas por el legislador.

Nuestro planteamiento remite, principalmente, a la idea de la no exclusividad del accionar de los usuarios en base a reglas como razones únicas y excluyentes para la acción, sino más bien como una pluralidad de razones, entre ellas, por ejemplo, la interacción de sujetos, que es un campo perfecto del estudio de la Neurociencia.

Por todo ello, la pérdida de hegemonía del positivismo jurídico abrió un espacio enorme para (re)reconsiderar el Derecho Natural y, con él, la posibilidad de entender el Derecho no como consecuencia de la actividad y voluntad del legislador, sino como el resultado de una única y monopólica fuente: la ley, sobre todo, como un ordenamiento de normas o resultados interpretativos de un elenco de fuentes.

Desde la discusión y la creación de las fuentes del Derecho atribuidas a Friedrich Karl von Savigny, a través de su metáfora hidráulica, aún no existe un teoría general de las fuentes del Derecho, de allí que su entendimien- 
to, por ende su clasificación, al día de hoy, es una verdadera interrogante. Si bien el concepto de fuente no es unívoco, existen distintos significados y diferentes interpretaciones sobre ello, por ejemplo, se denomina fuente a «(...) toda clase de actos que estén autorizados a producir normas, aun si por casualidad determinado acto de aquella clase, carezca de contenido normativo» ${ }^{10}$. Bajo esta línea de razonamiento, solo los actos que estén autorizados — actos dotados de autoridad — son aquellos que pueden producir normas; sin embargo, esta idea no es del todo cierta ya que hay actos — no dotados de autoridad - que producen normas, en consecuencia, a partir de ello podemos proponer la siguiente clasificación de fuentes con relación a lo siguiente:

a) Un ámbito escrito, expreso, verbalizado, legislado, denominado Derecho Formal, está conformado por fuentes como i) principios formales, ii) leyes, iii) jurisprudencia y, iv) doctrina; todas con la característica de tener una actuación espontánea, mínimamente expresa o verbalizada, y, de sufrir crisis de cooperación ${ }^{11}$, solicita la actuación forzosa a través de la Tutela Jurisdiccional.

b) Un ámbito no escrito, tácito, no verbalizado, denominado Derecho $M u d o^{12}$, que está conformado por fuentes como: i) la costumbre, ii) los principios de remisión abierta, y iii) la interacción cotidiana de los sujetos; esta última conformada a su vez por acciones provocadas por deseos, creencias y emociones. Dichas fuentes tienen la característica de tener una actuación espontánea muda o tácita, y de sufrir crisis de cooperación muta y se ajusta al Derecho formal para tener actuación forzosa a través de la Tutela Jurisdiccional.

A raíz de la clasificación de estos dos elencos de fuentes — verbalizado y no verbalizado o formal e informal-, corresponde entender al Derecho como un ordenamiento normativo, es decir, el Derecho es siempre norma; sin embargo, esto no supone que toda entidad normativa en el Derecho

10 Cfr. GUASTINI, Riccardo. Las fuentes del derecho: fundamentos teóricos. Trad. César E. Moreno. Lima: Raguel, 2016, pp. 100 y ss.

11 «Es lo que impide al titular de la situación de ventaja obtener todas aquellas utilidades que el derecho sustancial le atribuye. En vista de la prohibición de autotutela privada, el titular del derecho debe, por lo tanto, necesariamente recurrir al proceso, instrumento con el cual solicita al Estado — representado por el Juez - una providencia que le permita disfrutar de la res...». PROTO PISANI, Andrea. La tutela Jurisdiccional. Lima: Palestra Editores, 2014, p. 30.

12 Para mayor profundidad, cfr. SACCO, Rodolfo. Il diritto muto: Neuroscienze, conoscenza tacita, valori condivisi. Bologna: Il mulino, 2015, p. 9. 
sea norma. Las normas existen por la existencia de otros componentes: las fuentes. El Derecho - por ende la norma - es el resultado interpretativo de sus fuentes.

En ese sentido, ¿qué tipo de normas son las que componen el ordenamiento normativo?, la respuesta, desde una perspectiva clásica, es «el ordenamiento está compuesto por normas originarias, derivadas, formuladas, expresas, metanormas, etc.» ${ }^{13}$. Sin embargo, el Derecho entendido como ordenamiento normativo no está compuesto solo por normas formales —verbalizadas—, sino también por normas tácitas — no verbalizadas-.

Hasta aquí, lo desarrollado ha tenido como objetivo identificar la participación de otro tipo de fuentes del Derecho, que nacen a raíz de la decadencia del positivismo jurídico y que forman y son parte del ordenamiento normativo, es así que percibimos la importancia de esta nueva fuente - interacción humana- que está a su vez expresada, específicamente, por las acciones de un sujeto y estas a su vez conformadas, particularmente, por deseos, creencias y emociones.

\section{LA IMPORTANCIA DE LAS EMOCIONES Y EL DERECHO}

«Las emociones — miedo, alegría, tristeza, ira, amor, odio, envidia, vergüenza, indignación, compasión, culpa, orgullo, admiración, celos, esperanza, remordimiento, sorpresa, gratitud, resentimiento, repugnancia, arrepentimiento, rencor, desdén, ilusión, desilusión, desesperación, entusiasmo, hastío- ocupan un puesto central en la vida del hombre, influyen en su manera de pensar, de percibir, de interpretar el mundo, de elegir objetivos de actuar.... ${ }^{14}$, es a raíz de ello que el jurista se interesa con la finalidad de entender la responsabilidad de las acciones del hombre y el reproche que merece otorgarle a conductas antijurídicas.

Si bien las emociones han sido el objeto de estudio de diversas disciplinas científicas, como la Filosofía, la Sociología, la Antropología, la Biología, la Medicina entre otras, estas no han sido descuidadas por la Filosofía del Derecho, sobre todo por los juristas del Civil Law; esto no sucede en el ámbito del Common Law, ya que existe un movimiento denominado Law and

13 Cfr. GUASTINI, Riccardo. Ob. cit., p. 619 y ss.

14 CAZARUS, R.S y LAZARUS, B. Pasión y Razón. La comprensión de nuestras emociones. Barcelona: Editorial Paidós, trad. De Montse Ribas Casellas, 2000, Cap. 12. 
Emotion $^{15}$. Este descuido de estudio asombra, ya que las emociones son un componente importante en la interacción de las personas en sociedad, porque influyen en sus comportamientos y en la toma de decisiones.

La relación entre las emociones y el Derecho puede ser formulada desde distintos ámbitos, por ejemplo, desde el plano del infractor de la norma, puesto que «....al derecho — especialmente al Derecho Penal— no le interesa exclusivamente el aspecto externo de las acciones, sino también las intenciones del agente...» ${ }^{16}$; no obstante, también desde el lado del Juez; con relación a lo último, «ison útiles ciertas emociones a la hora de juzgar y aplicar el derecho, o por el contrario, los jueces deben despojarse de ellas?» ${ }^{17}$.

Las emociones pueden ser consideradas como puntos ciegos, como predisposiciones y sensaciones de actuar de una u otra manera, con la característica peculiar de que no tienen un contenido significativo ni mucho menos racional — fuera de la razón-.

El intento de explicar el papel de las emociones en el proceso de la toma de decisiones fue desarrollado por el neurólogo Antonio Damasio. El autor construye su hipótesis con relación al entendimiento clásico de la racionalidad. Señala, que cuando un sujeto - persona - se enfrenta a una situación en la que se debe tomar una decisión, su cerebro elabora una serie de respuestas o alternativas y sus correspondientes resultados; "para nuestra conciencia los supuestos están formados por múltiples escenas imaginarias, no realmente como una película ininterrumpida, sino más bien como destellos pictóricos de imágenes clave de dichas escenas» ${ }^{18}$, por tanto ¡cómo podría escogerse entre distintas opciones, supuestos y alternativas que se presentan?

Damasio refiere que la postura tradicional de la racionalidad dispone que para decidir previamente debe realizarse una evaluación, un análisis de cada opción, supuesto o alternativa en función de los costes y beneficios esperados, es decir, se debe atribuir a cada respuesta un valor adicional de ventaja o desventaja. La tarea no parece fácil, la racionalidad puede elaborar una lista interminable de opciones y cada una de ellas puede tener

15 LITTLE, L. E. «Negotiating the Tangle of Law and Emotion». En Cornell Law Review 86, 974. New York: Cornell University, 2000.

16 GONZALES, Daniel. Emociones, responsabilidady Derecho. Madrid: Marcial Pons, 2009, p. 16.

17 Cfr. Ibidem, p. 18 y ss.

18 DAMASIO, A.R. El error de Descartes. La emoción la razón y el cerebro humano. Trad. De Joandomenec Ros. Barcelona: Editorial Andrés Bello, 2004, p. 201. 
distintos escenarios de pros y contras, por lo tanto «si dicha estrategia es la única opción de la que disponemos, la racionalidad (...) no funcionará. En el mejor de los casos, nuestra decisión tomará un tiempo excesivamente largo, mucho más de lo que sería aceptable, si ese día hemos de hacer alguna otra cosa. En el peor de los casos, puede incluso que no acabemos tomando una decisión, porque nos habremos perdido en los desvíos de nuestro cálculo» ${ }^{19}$.

Hay que tener en cuenta, que el proceso evolutivo del hombre está marcado por la toma de decisiones a cada instante, esto implica que ocupar un tiempo para evaluar racionalmente cada opción, supuesto o alternativa para decidir, causaría un perjuicio en nuestro desarrollo, en consecuencia, concuerdo con el autor en que las cosas no funcionen así.

La respuesta, según Damasio, es que cuando el cerebro se llena de distintas alternativas de decisión junto con sus posibles resultados, algunas de ellas se conectan con sensaciones agradables y desagradables. A estas sensaciones Damasio las denomina marcadores somáticos y estos «...fuerzan la atención sobre los resultados negativos y positivos y pueden hacer que rechacemos la alternativa por ese curso de acción, con lo que, en la práctica, el razonamiento opera con un número significativamente menor de alternativas. Pues bien los marcadores somáticos no son otra cosa que las emociones ${ }^{20}$.

Para tener más claro este escenario, Damasio nos lo explica con el siguiente ejemplo:

[...]Elliot, era un hombre de negocios con una vida familiar satisfactoria, hasta que se operó un tumor en la meninges - una zona del cerebro asociada a las emociones- A partir de entonces Elliot pareció perder su capacidad para gobernar su vida: realizó negocios desastrosos, se divorció, se casó y se divorció de nuevo, perdió sus amistades etc. En las pruebas que se le hicieron mostró un comportamiento normal de la sociedad y una plena capacidad de la memoria, uso del lenguaje, atención, razonamiento básico, etc. Sin embargo, presenta una reducción de sus reacciones emocionales, y si tenía que tomar una decisión (aunque fuera tan trivial como para concertar una nueva cita), podía pasar horas analizando los pros y contras de cada alternativa, sin llegar nunca a decidirse (aunque luego aceptara sin más cualquiera de las soluciones que le propusieran.

19 Cfr. ibidem, pp. 203.

20 GONZALES, Daniel. Ob. cit., p. 119. 
Por consiguiente, la toma de decisiones no es racional ni lógica, está marcada por la emoción; es más habría que considerar que la mayoría de las veces la toma de decisiones es automática. Ello no implica una sustitución de la razón por las emociones, sino una colaboración entre ellas, lo que se hace entonces es justificar racionalmente la decisión que tomamos impulsados por la emoción, es decir, lo racional es la justificación de la decisión emocional. Asimismo, las emociones contribuyen al proceso de decisión generando una sensación de urgencia necesaria para tomar la decisión a tiempo.

\section{LA DECISIÓN EMOCIONAL DEL JUEZ EN EL PROCESO}

Las emociones en el proceso dominaron por mucho tiempo la justificación de las decisiones del juez, ello a raíz de la interacción del magistrado con las partes procesales, es ahí, donde se olvidó que toda interacción en el proceso ineludiblemente se expone emocionalidad entre los sujetos, ya que, en tanto estos sean humanos, esto siempre será así.

Si bien los primeros actos de comunicación entre los actores del proceso se dan con la interposición de la demanda, es en la audiencia donde coexiste una mayor interrelación de todas las partes en el proceso; es decir, allí se genera una comunicación procesal que puede abarcar tanto el ámbito formal como el tácito, que se puede expresar de la siguiente manera:

a) Comunicación procesal formal, se refiere al lenguaje escrito y/o hablado, v. gr., imperativos procesales — deberes, obligaciones y cargas-, actos de partes, actos del juez —oficios, exhortos y notificaciones-. Esta comunicación procesal tiene un amplio espectro de realización sobre todo en la actividad probatoria, y la hermenéutica que abarca es la tradicional - legal—.

b) La comunicación procesal tácita se refiere al lenguaje no verbalizado, $v$. gr. lenguaje corporal y circunstancialidad emocional en la conducta procesal. Esta comunicación, al no ser formal, es incógnita, es decir, al ser muda es estrictamente ecológica ${ }^{21}$, y no puede servirse de la hermenéutica de la comunicación expresa, ella es insuficiente para la interpretación de los actos mudos. Aquí corresponde ver una neurohermenéutica.

21 La interacción de los seres vivos entre sí. 
En ese sentido, el juez al tener una interacción con las partes, ya sea a través de una demanda o a través de una audiencia, acoge un deber: estar predispuesto a escuchar las miserias de las partes; es decir, el juez tendrá que familiarizarse con las emociones de los procesados, en consecuencia, sin saberlo, establecerá una conexión emocional distinta con cada una de las partes, por ejemplo, con la agraviada o el demandante compasión, empatía, protección, amparo, defensa, entre otras, y por otro lado, con el imputado o demandado desprecio, rechazo, indignación, ira, etc.

El juez no es consciente de que adoptó esa conexión, lo que sucede es que su cerebro límbico — ese que gobierna las emociones - se percató de esta comunicación tácita, no verbalizada, no consciente o simplemente muda; por ende, la justificación de una decisión judicial está en base a emociones, consecuencia de la comunicación muda emocional del juez con la interacción con los justiciables y con los actos procesales, la cual no es racionalmente reparada porque nace en la zona límbica del cerebro del juez.

Pareciera que la asignación de una dosis de racionalidad a la motivación de las decisiones judiciales logró conjurar las emociones del proceso, aun con los riesgos de la inmediación, con la idea de que una decisión sujeta a los hechos del caso concreto y al ordenamiento normativo es una decisión justa, es decir, en tanto más objetiva sea la decisión será entendida como más justa; sin embargo, la subjetividad — que es como se visualiza a la emocionalidad - corroe la justicia de la decisión judicial.

Si es así, ¿el juez podrá ser imparcial? — teniendo en cuenta que la imparcialidad comprende la independencia del juez y que en su plano interno, implica la asepsia de emocionalidad, porque esta puede pervertir la (re) construcción de los hechos del caso concreto sin que el juez lo repare racionalmente-, la respuesta es no, ya que la mente judicial está corrompida, contaminada. El juez decide en base a sus emociones, por consiguiente, si en él existe una predisposición emocional, que no está en la posibilidad de modificar o controlar, entonces no puede ser imparcial. Si no hay imparcialidad, entonces no hay objetivismo, justicia ni equidad.

La lectura de esta interferencia emocional en la decisión judicial solo podría darse a nivel Neurocientífico, propiamente, con aquello que podemos denominar neurohermenéutica, es decir, solo podría interpretarse por una lectura de la actividad eléctrica cerebral gracias a la Neurociencia y en ellas, propiamente, por el uso de la tecnología de la Functional magnetic resonan- 
ce imaging (fMRI $)^{22}$, que permite medir la variación de los flujos sanguíneos en determinadas áreas cerebrales, así mismo permite ver las regiones cerebrales que se activan o trabajan con determinada operación mental del Juez, técnica interpretativa que seguramente no demorará mucho tiempo en tomar cuerpo teórico.

\section{PROPUESTAS PARA LOGRAR EL OBJETIVISMO EN EL PROCESO}

Con la finalidad de salvaguardar el objetivismo de la justicia y la equidad, y es que en puridad, para evitar esta teátrica intervención de los sujetos procesales y, por tanto, la afectación de las decisiones judiciales por parte de las emociones, proponemos lo siguiente:

a) Un control de las emociones por medio de la manipulación del contexto en el que surgen, es decir que el juez sepa y sea consciente de las circunstancias o condiciones que despiertan emociones en él y las que desea controlar, lo cual parece ser una tarea difícil; sin embargo sería una manera de suprimir las condiciones que hacen que surjan las emociones. Esta propuesta nace de aquello que podemos denominar educación emocional, ya que para evitar la injerencia de las emociones en las decisiones judiciales corresponde previamente que el juez comprenda su propia naturaleza, las motivaciones humanas y reconozca sus emociones, a partir de ello recién se disponga a adaptar la norma al caso concreto, para evitar el enjuiciamiento prima facie $^{23}$.

b) Un proceso con inmediación como el que ya existe, pero con una configuración de técnica procedimental particular, el cual prevea un juez instructor y otro de sentencia. Esta técnica está sujeta a la mecánica de contaminar en la menor medida posible la imparcialidad del juez. Este último no dejará de tener emocionalidad en el caso concreto, eso es cierto, pero en la mayor medida posible reducirá su emocionalidad.

Si bien resulta necesario e imprescindible un proceso siempre con inmediación —interacción de los sujetos procesales_-, sin embargo, nos hemos dado cuenta que esta comunicación neuroecológico — procesal resulta

22 TARUFFO, Michele y NIEVA, Jordi (Dirs.). Neurociencia y proceso judicial. Madrid: Marcial Pons, 2013, p. 20.

23 NIEVA, Jordi. El elemento psicológico en la adopción de las medidas cautelares. Barcelona: Universidad de Barcelona, 2007. 
determinante en la toma de decisiones del juez, en la medida en que el orden emocional siempre tendrá presencia en la mente del juzgador lo que al pasar desapercibido por la racionalidad del hombre - juez solo podría ser descifrado por una interpretación, y consecuente motivación, que solo estaría en los alcances de la Neurociencia.

\section{CONCLUSIONES}

1. Siempre se ha omitido la comunicación tácita, emocional o muda en el proceso. El influjo de la Neurociencia empieza a proyectarse en mayores espacios procesales, de los que la decisión del juez no puede escapar.

2. La incorporación de nuevas fuentes, como las no verbalizadas, particularmente la interacción de usuarios a través de sus acciones y específicamente de sus emociones, presenta una nueva concepción sobre cómo debe entenderse el Derecho y el ordenamiento normativo.

3. La decisión judicial, por ser actividad humana fruto de una interacción procesal no puede dejar de tener un componente emocional, en mayor o menor proporción, pero siempre en alguna medida; por tanto, la motivación de esa decisión no solo es la que permite el cerebro analítico o racional, sino también el escenario del cerebro emocional - límbico- del juez, que según la Neurociencia, domina la forma cómo se construye una decisión judicial y que su interpretación solo estaría a cargo del neuroderecho, propiamente de la neurohermenéutica jurídica. 